BNL-113829-2017-JA

\title{
Comparison of Methodologies of Activation Barrier Measurements for Reactions with Deactivation
}

\author{
Zhenhua Xie, Binhang Yan, Li Zhang, Jingguang G. Chen
}

Submitted to Industrial \& Engineering Chemistry Research

February 2017

Chemistry Department

Brookhaven National Laboratory

\author{
U.S. Department of Energy \\ USDOE Office of Science (SC), \\ Basic Energy Sciences (BES) (SC-22)
}

Notice: This manuscript has been authored by employees of Brookhaven Science Associates, LLC under Contract No. DE- SC0012704 with the U.S. Department of Energy. The publisher by accepting the manuscript for publication acknowledges that the United States Government retains a non-exclusive, paid-up, irrevocable, world-wide license to publish or reproduce the published form of this manuscript, or allow others to do so, for United States Government purposes. 


\section{DISCLAIMER}

This report was prepared as an account of work sponsored by an agency of the United States Government. Neither the United States Government nor any agency thereof, nor any of their employees, nor any of their contractors, subcontractors, or their employees, makes any warranty, express or implied, or assumes any legal liability or responsibility for the accuracy, completeness, or any third party's use or the results of such use of any information, apparatus, product, or process disclosed, or represents that its use would not infringe privately owned rights. Reference herein to any specific commercial product, process, or service by trade name, trademark, manufacturer, or otherwise, does not necessarily constitute or imply its endorsement, recommendation, or favoring by the United States Government or any agency thereof or its contractors or subcontractors. The views and opinions of authors expressed herein do not necessarily state or reflect those of the United States Government or any agency thereof. 


\section{Comparison of methodologies of activation barrier}

\section{measurements for reactions with deactivation}

Zhenhua Xie ${ }^{\mathrm{a}, \mathrm{b}, \ddagger}$, Binhang Yan ${ }^{\mathrm{c}, \ddagger}$, Li Zhang ${ }^{\mathrm{a}, *}$, Jingguang G. Chen ${ }^{\mathrm{b}, \mathrm{c}, *}$

${ }^{a}$ College of Power Engineering, Chongqing University, Chongqing 400044, China

${ }^{\mathrm{b}}$ Department of Chemical Engineering, Columbia University, New York, NY 10027, United States

${ }^{\text {c }}$ Chemistry Department, Brookhaven National Laboratory, Upton, NY 11973, United States

KEYWORDS: methodology, activation barrier, deactivation.

ABSTRACT: Methodologies of activation barrier measurements for reactions with deactivation were theoretically analyzed. Reforming of ethane with $\mathrm{CO}_{2}$ was introduced as an example for reactions with deactivation to experimentally evaluate theses methodologies. Both the theoretical and experimental results showed that due to catalyst deactivation, the conventional method would inevitably lead to a much lower activation barrier compared to the intrinsic value, even though heat and mass transport limitations were excluded. In this work, an optimal method was identified in order to provide a reliable and efficient activation barrier measurement for reactions with deactivation. 


\section{INTRODUCTION}

Activation barrier is a critical parameter for kinetic studies, however, it cannot be obtained reliably and accurately due to the heat/mass transport effects, and catalyst deactivation as well ${ }^{1}$. The former usually leads to significant concentration and temperature gradients within the individual catalyst particle and catalyst bed, resulting in much lower activation barriers ${ }^{2,}{ }^{3}$. Significant efforts have been paid to remove the transport effects via increasing space velocity, decreasing particle size or intra-/inter-particle dilution. ${ }^{1}$ In contrast, the effect of deactivation on activation barrier measurements was few studied. Catalyst deactivation is a common issue for several reactions, such as dry/steam reforming ${ }^{4}$, oxidative dehydrogenation ${ }^{5}$ and partial oxidation ${ }^{6}$, which might be due to metal sintering ${ }^{7}$, coke deposition ${ }^{7}$, and other deactivation mechanisms. The significant deactivation makes it difficult for the measurements of steady-state reaction rates and therefore the activation barrier. This hinders the understanding of intrinsic

kinetics, and the combination of experiments with DFT calculations in microkinetic modeling ${ }^{8}$ as well. Therefore, it is critical for the benchmarking ${ }^{9}$ in catalysis science to identify methods for measuring activation barriers without being affected by the transport limitations and catalyst deactivation.

The widely used method is to measure the reaction rate using fresh catalysts each time at different temperatures, which is not only time-consuming but also influenced by deactivation. In this work, three methods were theoretically and experimentally evaluated, then an optimal method of activation barrier measurements for reactions with deactivation was identified.

\section{THEORETICAL AND EXPERIMENTAL METHODS}



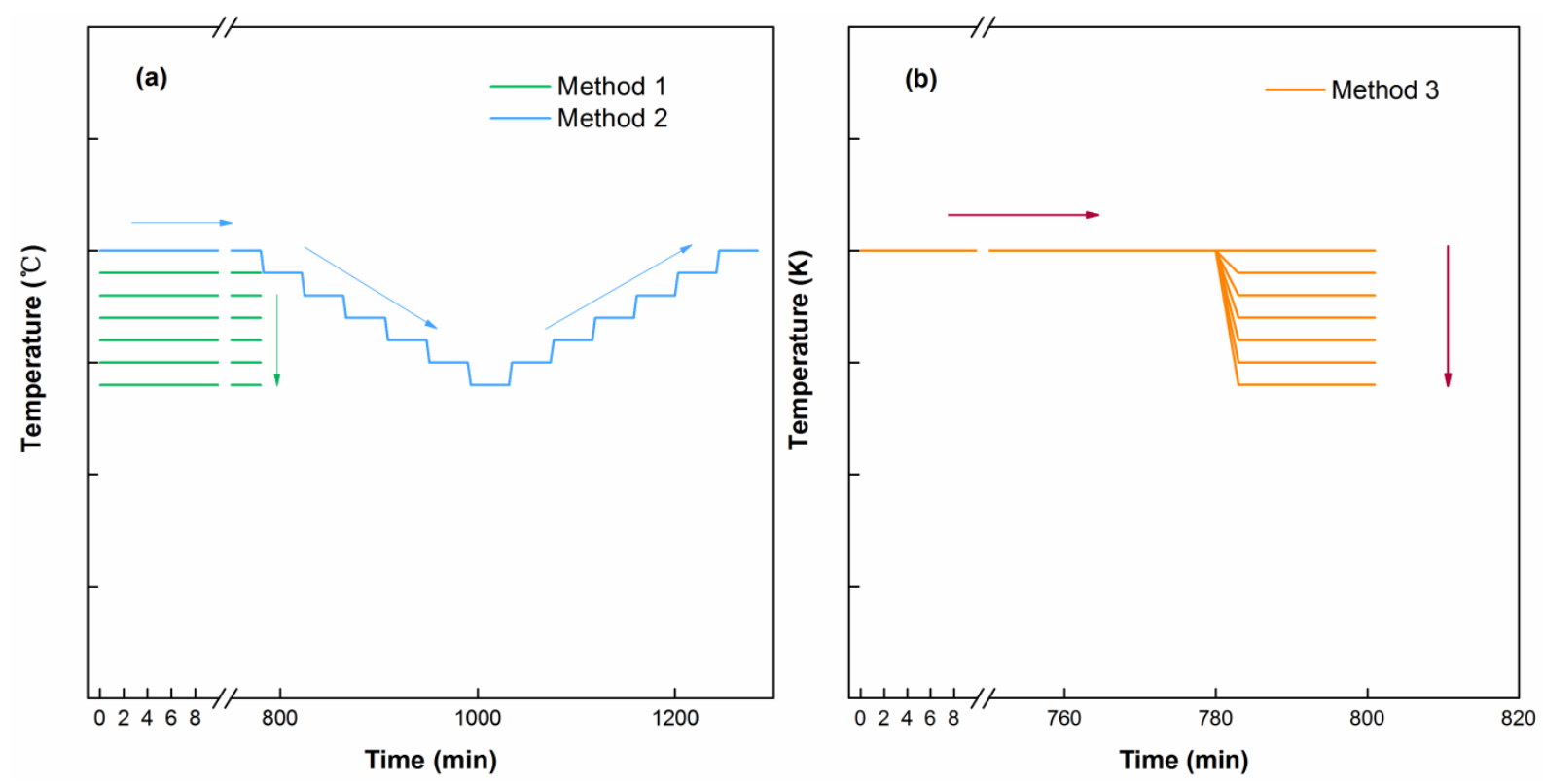

Figure 1. Temperature-changing profiles of (a) Methods 1 and 2, and (b) Method 3.

Figure 1 illustrates the temperature-changing profiles for various methods: Method 1 uses a fresh catalyst at each temperature to reach the pseudo-steady state (PSS), then the reaction rate at PSS is used to estimate the activation barrier based on the linear relationship between $\ln$ (rate) and 1000/T; Method 2 uses only one fresh catalyst at the highest temperature in the temperature sequence to reach the PSS, then subsequently follows a decreasing and an increasing temperature sequences to obtain the averaged reaction rate at each temperature; Method 3 is similar to Method 1 except that each time a fresh catalyst is treated at the highest temperature to reach the PSS before changing to the desired temperature.

An simplified power law kinetic model with second-order order deactivation ${ }^{3}$ was established in this work in order to theoretically compare and evaluate these three methods. Since most catalyst deactivation is essentially due to the loss of active sites, the deactivation of catalyst was simply depicted by a second-order power expression ${ }^{3}$ in the following theoretical analysis. It should be 
noted that similar derived results could be obtained by using first-order power expression for deactivation.

$r_{d}=-\frac{d \alpha}{d t}=k_{d} \alpha^{2}$

Therefore, the measured reaction rate at a given time $(t)$ and temperature (i) could be represented by a simplified power law equation ${ }^{3}$ :

$r_{t, i}=r_{0} \alpha=k P_{A}^{m} P_{B}^{n} \alpha$

The least square method ${ }^{10}$ was introduced to obtain the slope of the resulting plot of $\ln (\mathrm{r})$ vs. 1000/T, which the activation barrier can be derived according to the slope value.

The reforming reaction of ethane with $\mathrm{CO}_{2}$ over $\mathrm{PtNi} / \mathrm{CeO}_{2}$ were employed as an example for the reactions with deactivation. The experimental procedures for different methods were specified in S2 of Electronic Supplementary Information (ESI). It should be noted that there were no heat and mass transport limitations in the present experimental conditions, which was experimentally and numerically validated in Ref. 11 .

\section{RESULTS AND DISCUSSION}

The theoretically derived activation barriers $\left(\Delta E_{m}\right)$ obtained via various methods (derived in ESI S1) are shown as follows:

\section{Method 1:}


$\Delta E_{m}=\Delta E+\frac{\sum_{i=0}^{N-1}\left(Q_{i}-\bar{Q}\right) \ln \left(a_{i} /\left(\prod_{i=0}^{N-1}\left(a_{i}\right)\right)^{\frac{1}{N}}\right)}{\sum_{i=0}^{N-1}\left(Q_{i}-\bar{Q}\right)^{2}}$

where $\left.a_{i}=1+k_{d, i} \exp \left[\Delta E_{d}\left(Q_{0}-Q_{i}\right)\right]\left(t_{0}+\tau\right)\right], Q_{i}=1 / R T_{i} . \Delta E$ and $\Delta E_{d}$ refer to the true activation barrier and deactivation activation barrier, respectively.

\section{Method 2:}

$\Delta E_{m}=\Delta E-\frac{\sum_{i}\left(Q_{i}-\bar{Q}\right) \ln \left(\frac{1 / a_{i}^{\prime}+1 / b_{i}^{\prime}}{\left(\prod_{i=0}^{N-1}\left(1 / a_{i}^{\prime}+1 / b_{i}^{\prime}\right)\right)^{\frac{1}{N}}}\right)}{\sum_{i}\left(Q_{i}-\bar{Q}\right)^{2}}$

where $a_{i}^{\prime}=1+k_{d, 0} t_{0}+k_{d, 0} \tau \sum_{i=0}^{i} \exp \left[\Delta E_{d}\left(Q_{0}-Q_{i}\right)\right], b_{i}^{\prime}=1+k_{d, 0} t_{0}+k_{d, 0} \tau \sum_{i=0}^{2 N-2-i} \exp \left[\Delta E_{d}\left(Q_{0}-Q_{i}\right)\right], Q_{i}$

$=1 / R T_{i}, N$ is the total number of temperature points in the temperature sequence, $\tau$ is the interval time between gas chromatography (GC) injections.

\section{Method 3:}

$\Delta E_{m}=\Delta E+\frac{\sum_{i}\left(Q_{i}-\bar{Q}\right) \ln \left(a_{i}^{\prime \prime} /\left(\prod_{i=0}^{N-1}\left(a_{i}^{\prime \prime}\right)\right)^{\frac{1}{N}}\right)}{\sum_{i}\left(Q_{i}-\bar{Q}\right)^{2}}$

where $a_{i}{ }^{\prime}=1+k_{d, 0} t_{0}+k_{d, 0} \exp \left[\Delta E_{d}\left(Q_{0}-Q_{i}\right)\right] \tau, Q_{i}=1 / R T_{i}$. 
It is quite complicated to rigorously simplify Eqs. (3)-(5) into simple linear algebra expressions. However, usually it takes a relatively long time $\left(t_{0}\right)$ for the reaction with deactivation to reach the PSS before obtaining the PSS reaction rate within for the activation barrier plot. For example, in the reaction of $\mathrm{C}_{2} \mathrm{H}_{6}$ with $\mathrm{CO}_{2}$ over $\mathrm{PtNi} / \mathrm{CeO}_{2}$ (described in the ESI S2), the time of $t_{0}$ and $\tau$ is $780 \mathrm{~min}$ and $21 \mathrm{~min}$, respectively, suggesting that the former is much longer than the latter, i.e., $t_{0}>>\tau$. Thus, the right items in both Eqs. (4) and (5) can be reduced to $\Delta E$ (ESI S1.2 and S1.3), i.e., the true activation barrier, whereas the second right item in Eq. (3) still cannot be ignored (ESI S1.1) and would play a significant role in the derived activation barrier, i.e., $\Delta E_{m}$. As shown in Eq. (A.13) and Figure S1 (ESI), the second right item in Eq. (3) is qualitatively negative, essentially reflecting the effect of catalyst deactivation, which makes $\Delta E_{m}$ much lower than $\Delta E$. This means that activation barriers would be underestimated even though many efforts have been paid to remove transport limitations. Generally, according to the mathematical comparison of these three methods, the accuracy of the three methods for activation barrier measurements follows the trend: Method $3 \approx$ Method $2>$ Method 1 .

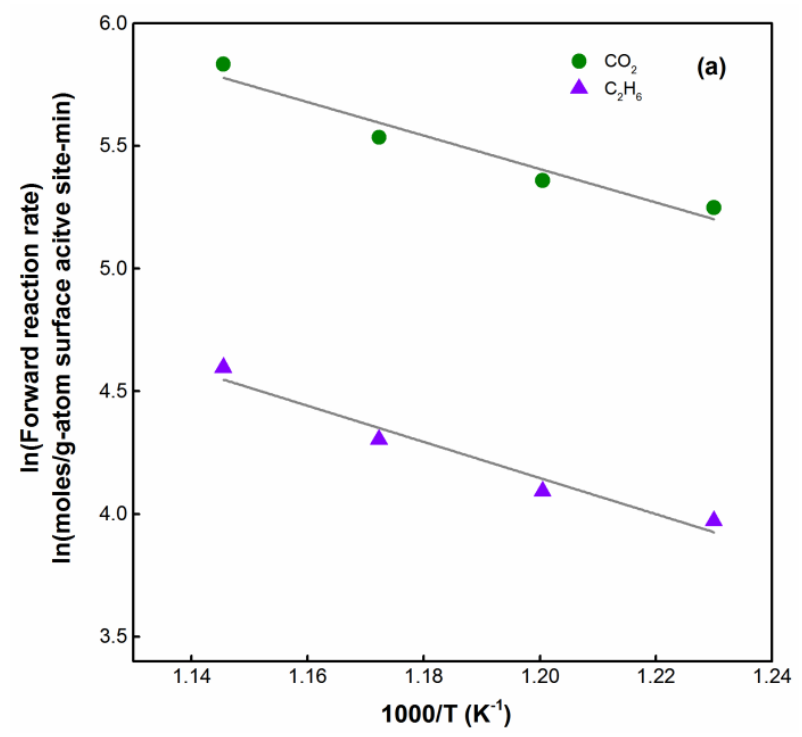



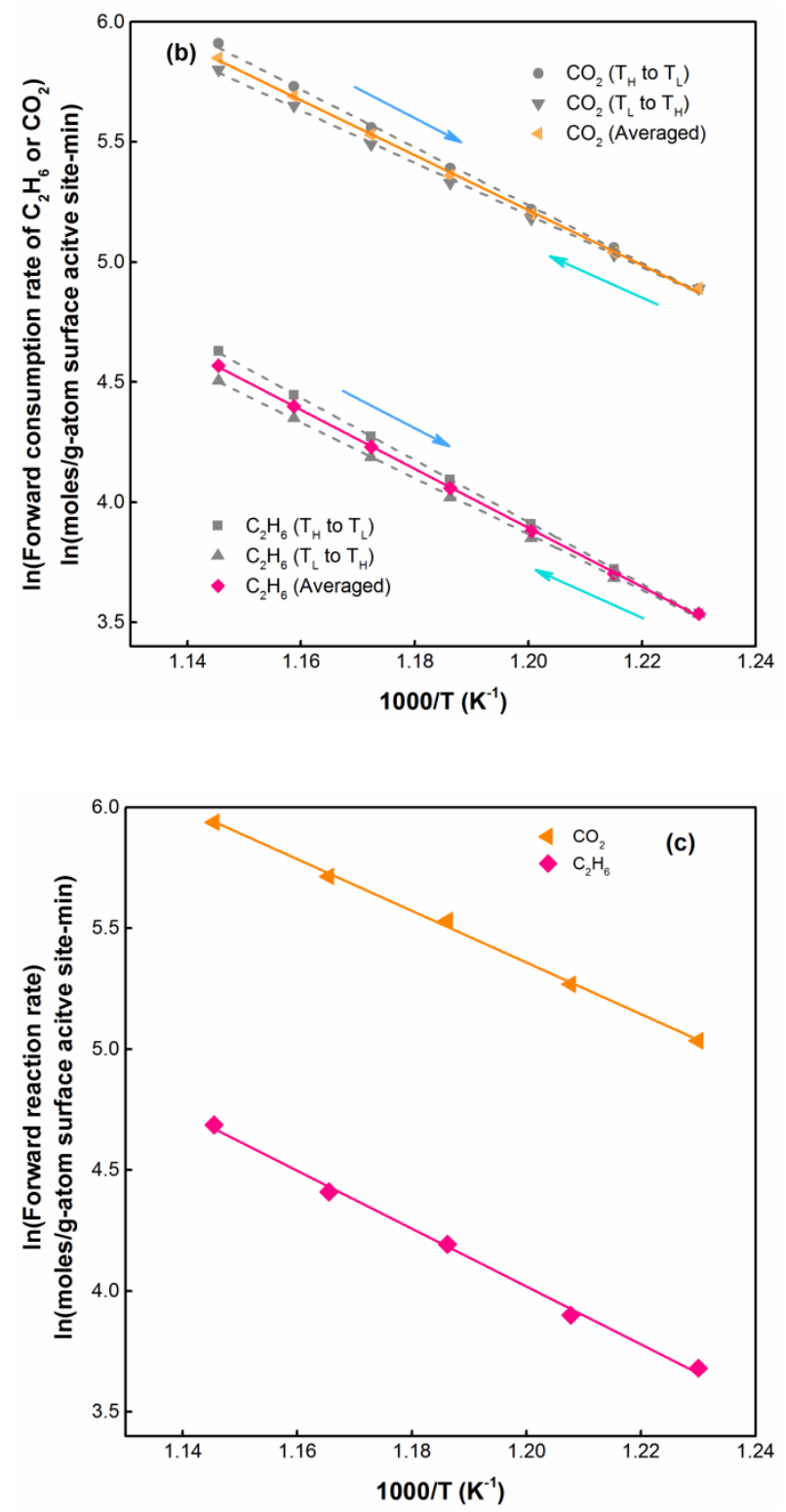

Figure 2. Natural logarithm of forward reaction rates as a function of $1000 / \mathrm{T}$ on $\mathrm{PtNi} / \mathrm{CeO}_{2}(\mathrm{~T}=$ 813-873 K, atmospheric pressure, $\mathrm{CO}_{2} / \mathrm{C}_{2} \mathrm{H}_{6} / \mathrm{Ar}=10 / 10 / 60 \mathrm{ml} / \mathrm{min}, \mathrm{m}_{\mathrm{PtNi} / \mathrm{CeO} 2}=5 \mathrm{mg}$, intradiluted with $\mathrm{SiO}_{2}$ (1:5), inter-diluted with acid-purified quartz (1:80), 40-60 mesh. Note: the data for Figure 2(b) were obtained from Ref. 11.

Table 1. Activation barriers and correlation coefficients for dry reforming of ethane over $\mathrm{PtNi} / \mathrm{CeO}_{2}$. 


\begin{tabular}{cccccccc}
\hline \multirow{2}{*}{ Method No. } & \multicolumn{3}{c}{ Activation barriers (kJ/mol) } & \multicolumn{2}{c}{ Correlation coefficients $\left(\mathrm{R}^{2}\right)$} \\
\cline { 2 - 7 } & $\mathrm{CO}_{2}$ & $\mathrm{C}_{2} \mathrm{H}_{6}$ & Reforming & RWGS & $\mathrm{CO}_{2}$ & $\mathrm{C}_{2} \mathrm{H}_{6}$ \\
\hline 1 & 57 & 61 & 60 & 55 & 0.9161 & 0.9379 \\
2 & $100^{\mathbf{a}}$ & $107^{\mathbf{a}}$ & - & - & 0.9987 & 0.9999 \\
& $95^{\mathbf{b}}$ & $102^{\mathbf{b}}$ & $104^{\mathrm{b}}$ & $87^{\mathrm{b}}$ & 0.9988 & 0.9996 \\
& $90^{\mathbf{c}}$ & $97^{\mathbf{c}}$ & - & - & 0.9982 & 0.9991 \\
\hline 3 & 89 & 99 & 101 & 76 & 0.9976 & 0.9960 \\
\hline
\end{tabular}

$\overline{\mathbf{a}}$ and ${ }^{\mathbf{c}}$ refer to the values obtained from the sequence of temperature decreasing and increasing processes in Figure 2(b), respectively. ${ }^{\mathbf{b}}$ : the data were obtained from Ref. 11.

In order to validate the theoretical analysis, the resulting plots for activation barriers with different methods are shown in Figure 2(a)-(c), and the related values for $\mathrm{CO}_{2}$ and $\mathrm{C}_{2} \mathrm{H}_{6}$ as well as reforming and reverse water gas shift (RWGS) reactions are summarized in Table $\mathbf{1}$. The idea to extract these values from the overall reaction of $\mathrm{CO}_{2}$ and $\mathrm{C}_{2} \mathrm{H}_{6}$ was specified in ESI S2. Method 1 resulted in activation barriers of 57 and $61 \mathrm{~kJ} / \mathrm{mol}$ for $\mathrm{CO}_{2}$ and $\mathrm{C}_{2} \mathrm{H}_{6}$, respectively, which were much lower than those from the other two methods (95 and $89 \mathrm{~kJ} / \mathrm{mol}$ for $\mathrm{CO}_{2}, 102$ and $99 \mathrm{~kJ} / \mathrm{mol}$ for $\mathrm{C}_{2} \mathrm{H}_{6}$ ). The activation barriers for reforming and RWGS reactions followed the same trend. Since there are no heat and mass transport limitations in the current experimental conditions ${ }^{11}$, the significant discrepancy in the activation barriers should essentially come from the deactivation. This is consistent with the prediction from Eq. (3) that the theoretically derived activation barrier will be lower than the true value due to deactivation.

According to the theoretical analysis, even though the equations of Methods 2 and 3 can be easily simplified with the assumption that $t_{0}>>\tau$, there is still little difference between these two methods. Experimentally, for Method 3 only one GC injection $(\tau)$ was performed after reaching PSS at each temperature as shown in $a_{i}^{\prime \prime}$, which means that the deactivation effect during the time of $\tau$ can be ignored compared to that before reaching PSS, as long as the condition of $t_{0}>>\tau$ is fulfilled in the experiments. Thus the obtained activation barrier should be nearly equal to the 
true value. In contrast, for Method 2, a sequence of GC injections was carried out during the temperature-changing recycle (i.e., $\mathrm{T}_{\mathrm{H}} \rightarrow \mathrm{T}_{\mathrm{L}} \rightarrow \mathrm{T}_{\mathrm{H}}$ ) as illustrated in Figure 1(a) and Figure 2(b), during which the deactivation effect would accumulate as represented by the third item in $a_{i}^{\prime}$ and $b_{i}^{\prime}$. This indicates that Method 2 shows a higher demanding for the fulfillment of $t_{0}>>\tau$ than Method 3. Otherwise, deactivation would lead to higher and lower activation barriers compared to the true values during the step-wise cooling and heating process, respectively, as illustrated by the gray dashed lines in Figure 2(b). However, the slope of the plot of $\ln (\mathrm{r})$ vs. 1000/T can be corrected by the average of the two points at the same temperature during the temperaturechanging cycle as indicated by the yellow and red lines in Figure 2(b). The quite similar activation barriers of Method 2 to those of Method 3 in Table 1 validate the feasibility of the correction by the average procedure. This suggests that Method 2 shows the promising capability to estimate the true activation barrier for reactions with deactivation. In addition, it is also extremely efficient in terms of the testing time since only one-time catalyst treat to reach the PSS is required for the entire temperature sequence.

The linearity of the $\ln (\mathrm{r})$ vs. 1000/T plots can be easily influenced by experimental errors such as intra-/inter-particle dilution errors, weighing error and gas-feeding fluctuation, etc. For highly active catalysts, the common method to exclude the heat and mass transport limitations is to perform intra-particle dilution ${ }^{12}$ of the pure catalyst with inert materials such as $\mathrm{SiO}_{2}$ and then weigh a small amount of the diluted catalyst for the test. In this case, the dilution and weighing errors among the parallel experiments would play a significant role in the measured reaction rates, therefore influence the linearity of the resulting plots. However, Method 2 is free of these experimental errors due to its inherent advantage of using only one fresh catalyst. As shown in Table 1, Method 2 shows an excellent linearity with the highest $\mathrm{R}^{2}$ of plots for $\mathrm{CO}_{2}$ and $\mathrm{C}_{2} \mathrm{H}_{6}$ 
(0.9988 and 0.9996, respectively), significantly outperforming the other two methods. As for reactions with less active catalysts, one can expect that the aforementioned errors would diminish since there is no need for catalyst dilution, and instead a large amount of catalyst is often weighed for the test. However, the time-consuming issue would still exist for the parallel experiments with Method 3.

In Method 2, the true activation barrier is obtained by using the mathematical treatment, i.e., the average procedure, however, this does not mean that intrinsic reaction rate or intrinsic preexponential factor can be obtained with this method since deactivation still exists. In this case, Method 3 seems to be the adequate alternative way to estimate the intrinsic pre-exponential factor. Both methods pretreat fresh catalysts at the highest temperature in the temperature sequence for a long time to reduce the deactivation effect at lower temperatures, in order to make sure the active sites are almost the same after reaching the PSS.

Even though this work is dedicated to the activation barrier measurements with temperatureinduced deactivation, addressing the pressure dependent deactivation kinetics is also important to complete the kinetic rate laws of deactivating catalysts. In the ESI S3, we still discussed several methods for the kinetic measurements with pressure-induced deactivation.

\section{CONCLUSIONS}

In summary, the commonly used Method 1 can deviate the measured activation barriers much far away from their true values due to catalyst deactivation even though the transport effects are excluded. In comparison, Method 2 is quite feasible by using traditional flow reactor experiments to obtain true activation barriers for reactions, especially with deactivation, benefiting from its only one-time catalyst treatment and being free of dilution and weighing 
errors. Method 3 is also reliable for activation barrier measurements, but it is time-consuming and can be easily affected by experimental errors.

\section{ASSOCIATED CONTENT}

\section{Supporting Information}

Derivation of theoretical activation barriers for different methods and experimental procedures for the examples with different methods. This material is available free of charge via the Internet at http://pubs.acs.org.

\section{AUTHOR INFORMATION}

\section{Corresponding Author}

*Tel.: 1 (212) 854 6166, Fax: 1 (212) 854 3054, Email: jgchen@columbia.edu (J. G. Chen); Tel: 86 (023) 651 03114, Fax: 86 (023) 651 11832, Email: lizhang@cqu.edu.cn (L. Zhang).

\section{Author Contributions}

The manuscript was written through contributions of all authors. All authors have given approval to the final version of the manuscript. $¥$ Both authors contributed equally to this work.

\section{Notes}

The authors declare no competing financial interest.

\section{ACKNOWLEDGMENTS}

The research was sponsored under contract DE-SC0012704 with the US Department of Energy. Z. Xie also acknowledges financial support from the China Scholarship Council and the Tang Lixin Scholarship. 


\section{NOTATIONS}

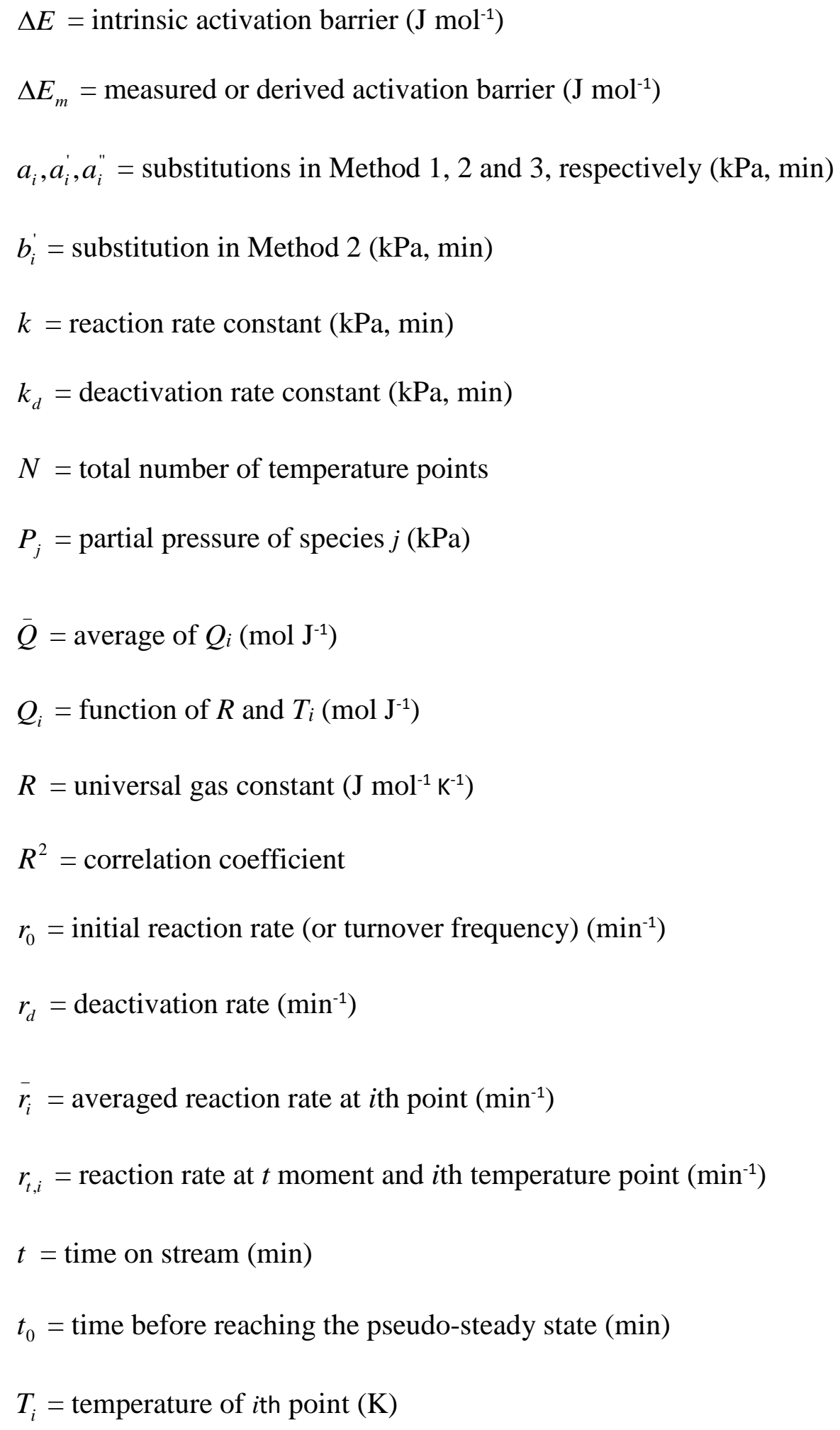


$\alpha=$ activity

$\tau=$ time between GC injections ( $\mathrm{min})$

\section{Subscripts}

0 = initial state

$d$ = deactivation of catalyst

$i=$ temperature point in the temperature sequence

$j=$ species $j$

$m=$ measured value from experiments or derived value from theoretical analysis

\section{REFERENCES}

1. $\quad$ Ertl, G.; Knözinger, H.; Schüth, F.; Weitkamp, J., Handbook of Heterogeneous Catalysis. 2008, Wiley, New York.

2. Mears, D. E., Tests for transport limitations in experimental catalytic reactors. Ind. Eng. Chem. Process Des. Dev. 1971, 10, 541-547.

3. Fogler H S. Elements of chemical reaction engineering. 2006, Prentice-Hall, New Jersey.

4. Pakhare, D.; Spivey, J., A review of dry $\left(\mathrm{CO}_{2}\right)$ reforming of methane over noble metal catalysts. Chem. Soc. Rev. 2014, 43, 7813-37.

5. $\quad$ Porosoff, M. D.; Myint, M. N. Z.; Kattel, S.; Xie, Z.; Gomez, E.; Liu, P.; Chen, J. G., Identifying Different Types of Catalysts for $\mathrm{CO}_{2}$ Reduction by Ethane through Dry Reforming and Oxidative Dehydrogenation. Angew. Chem., Int. Ed. 2015, 54, 15501-15505.

6. $\quad$ Peterson, E. J.; Delariva, A. T.; Lin, S.; Johnson, R. S.; Guo, H.; Miller, J. T.; Hun, K. J.; Peden, C. H.; Kiefer, B.; Allard, L. F., Low-temperature carbon monoxide oxidation catalysed by regenerable atomically dispersed palladium on alumina. Nat. Commun. 2014, 5, 4885-4885. 
7. Forzatti, P.; Lietti, L., Catalyst deactivation. Catal. Today 1999, 52, 165-181.

8. Salciccioli, M.; Stamatakis, M.; Caratzoulas, S.; Vlachos, D. G., A review of multiscale modeling of metal-catalyzed reactions: Mechanism development for complexity and emergent behavior. Chem. Eng. Sci. 2011, 66, 4319-4355.

9. $\quad$ Bligaard, T.; Bullock, R. M.; Campbell, C. T.; Chen, J. G.; Gates, B. C.; Gorte, R. J.; Jones, C. W.; Jones, W. D.; Kitchin, J. R.; Scott, S. L., Toward Benchmarking in Catalysis Science: Best Practices, Challenges, and Opportunities. ACS Catal. 2016, 6, 2590-2602.

10. Watson, G. S., Linear Least Squares Regression. Ann. Math. Stat. 1967, 38, 1679-1699.

11. Xie, Z.; Yan, B.; Zhang, L.; Chen, J. G., Effects of oxide supports on the kinetics of $\mathrm{CO}_{2}$ reduction by ethane over Pt-Ni bimetallic catalysts. J. Catal. 2016, submitted.

12. Koros, R.; Nowak, E., A diagnostic test of the kinetic regime in a packed bed reactor. Chem. Eng. Sci. 1967, 22, 470. 


\section{Abstract Graphics}
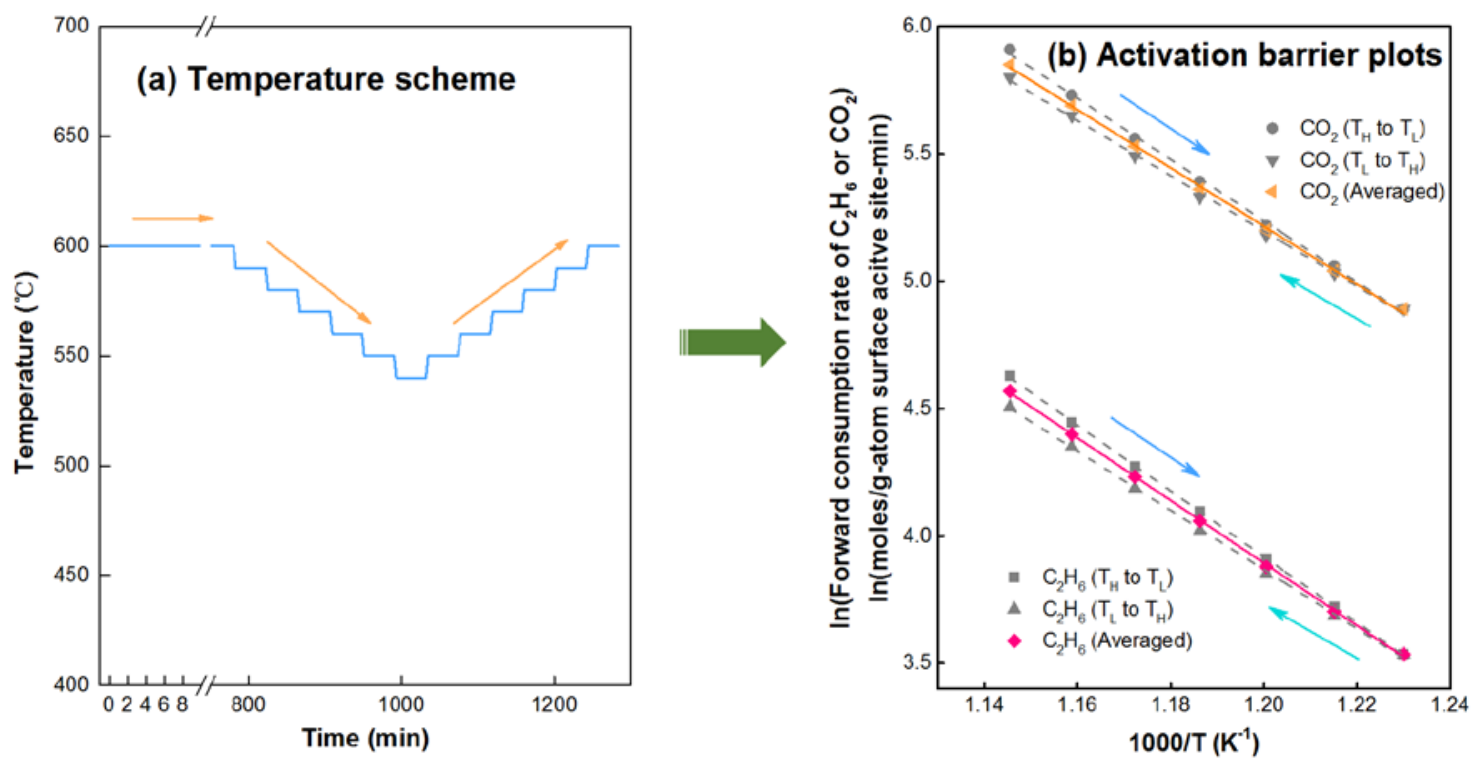

In the present work, theoretical models were established to evaluate the methodologies for activation barrier measurements; failure of the widely used method for activation barrier tests with deactivation was validated; a reliable and efficient method was identified for the reactions with deactivation. 